\title{
Programa educação conectada: o uso de tecnologia para o cumprimento das metas de educação básica no plano nacional de educação
}

\author{
Connected education program: the use of technology to comply with \\ the basic education goals in the national education plan
}

\author{
1 Renan Eduardo da Silva renan.silva@ifc.edu.br \\ 2 Monalisa Alberton Casagrande
}

1 Mestrando no Programa de Pós-Graduação Stricto Sensu da Universidade do Oeste de Santa Catarina - UNOESC.

2 Pós-graduanda em Direito Administrativo pela Universidade do Oeste de Santa Catarina - UNOESC Chapecó.

\section{Resumo}

O presente artigo pretende analisar a utilização de tecnologia pelo Programa Educação Conectada para cumprimento das metas para a educação básica no Plano Nacional de Educação. O trabalho de pesquisa utiliza do procedimento metodológico da pesquisa bibliográfica-investigativa que integra uma ampla investigação na legislação sobre o programa governamental em estudo. Desse modo, a pesquisa contempla 3 etapas: inicialmente, busca-se um entendimento sobre o Plano Nacional de Educação e suas metas; em seguida, são feitas breves considerações sobre políticas públicas para a educação básica. Com uma compreensão sobre políticas públicas para a educação básica, o tópico final procura demonstrar o Programa Educação Conectada como um programa governamental que procura aliar o uso de tecnologia como ferramenta pedagógica para a realização das metas de educação básica do Plano Nacional de Educação, nos ensinos fundamental e médio. Ante o exposto, as conclusões da pesquisa investigativa apontam uma expressiva adesão de escolas e municípios ao programa governamental, de modo que o desenvolvimento de ações voltadas ao emprego de tecnologia educacional, pela universalização do acesso à internet de alta velocidade e fomento de tecnologias pedagógicas digitais, constituem em importantes meios para o cumprimento das metas para educação básica constantes no Plano Nacional de Educação.

\section{Palavras-chave}

Plano nacional de educação. Programa educação conectada. Tecnologia.

\begin{abstract}
This article aims to analyze the use of technology by the Connected Education Program to meet the goals for basic education in the National Education Plan. The research work uses the methodological procedure of bibliographic-investigative research that integrates a broad investigation into government legislation on the government program under study. In this way, the research covers 3 stages: initially, an understanding of the National Education Plan and its goals is sought, then brief considerations about public policies for basic education are made. With an understanding of public policies for basic education, the final topic seeks to demonstrate the Connected Education Program as a government program that seeks to combine the use of technology as a pedagogical tool to achieve the basic education goals of the National Education Plan, in teaching fundamental and medium. Given the above, the conclusions of the investigative research point to an expressive adhesion of schools and municipalities to the government program, so that the development of actions aimed at the use of educational technology, through the universalization of high-speed Internet access and the promotion of Digital teaching technologies are an important means of achieving the basic education goals contained in the National Education Plan.
\end{abstract}

\section{Keywords}

National education plan. Connected education program. Technology.

\section{Como você deve citar?}

SILVA, Renan Eduardo da; CASAGRANDE, Monalisa Alberton. Programa educação conectada: o uso de tecnologia para o cumprimento das metas de educação básica no plano nacional de educação. Cadernos UniFOA, Volta Redonda, n. 43, p.109-120, agosto 2020. 
Programa educação conectada: o uso de tecnologia para o cumprimento das metas de educação básica no plano nacional de educação

\section{INTRODUÇÃO}

A educação básica brasileira vem sendo construída sobre a perspectiva da garantia de formação comum indispensável para o pleno desenvolvimento da pessoa, preparo para o exercício da cidadania e qualificação para o mercado de trabalho, como exposto nos artigos 205 e 206 da Constituição Federal (BRASIL, 1988).

A universalização do ensino básico é um dos objetivos mais importantes do Estado na busca pela educação como um direito ao alcance de todos. Para atender a este e outros objetivos, a Constituição Federal preceitua o estabelecimento de um Plano Nacional de Educação com metas e estratégias específicas para o desenvolvimento da educação básica no Brasil.

Nesse âmbito, o Ministério da Educação é responsável pela formulação de políticas públicas ou programas governamentais que visam atender às diretrizes para educação básica constantes no Plano Nacional de Educação. Uma das iniciativas no âmbito dos programas governamentais voltados à educação básica é o Programa Educação Conectada, o qual emprega tecnologia para universalização do acesso à internet em alta velocidade e fomento ao uso pedagógico de tecnologias digitais.

Portanto, com base em uma ampla pesquisa na legislação governamental sobre o Plano Nacional de Educação e políticas públicas educacionais, o presente estudo analisa o desenvolvimento do Programa Educação Conectada e a articulação de suas ações com foco na tecnologia para cumprimento das metas para educação básica inscritas no Plano Nacional de Educação, nos ensinos fundamental e médio.

\section{PLANO NACIONAL DE EDUCAÇÃO E SUAS METAS PARA A EDUCAÇÃO BÁSICA}

Consoante a seu reconhecimento como um dos direitos humanos ${ }^{3}$ e devido a seu papel essencial à dignidade humana ${ }^{4}$, o direito à educação no Brasil possui tratamento especial no texto constitucional. Conforme previsto no artigo $6^{\circ}$ e artigos 205 a 214 da Constituição Federal, a educação é consagrada como um direito de natureza fundamental ${ }^{5}$, direito de todos e dever do Estado que deve ser promovido e incentivado em colaboração com a sociedade ${ }^{6}$.

3 Declaração Universal dos Direitos Humanos. Art. 26, I - Todo ser humano tem direito à instrução. A instrução será gratuita, pelo menos nos graus elementares e fundamentais. A instrução elementar será obrigatória. A instrução técnico-profissional será acessível a todos, bem como a instrução superior, esta baseada no mérito. Disponível em: https://nacoesunidas.org/wp-content/uploads/2018/10/DUDH.pdf. Acesso em: 10/04/2019.

4 Segundo Silva e Masson (2015, p.368), a educação tem sido um pré-requisito para a expansão de outros direitos, já que a efetivação da cidadania registra a necessária condição de possibilidade de participação na vida social e política, para o que não se encontra caminho sem uma educação de qualidade que desenvolva o senso analítico e crítico.

5 Para Sarlet (2001, p.11), os direitos fundamentais podem ser conceituados como aquelas posições jurídicas concernentes às pessoas, que, do ponto de vista do direito constitucional positivo, foram, por seu conteúdo e importância (fundamentalidade material), integradas ao texto da Constituição e, portanto, retiradas da esfera de disponibilidade dos poderes constituídos (fundamentalidade formal), bem como as que, pelo seu objeto e significado, possam lhes ser equiparados, tendo, ou não, assento na Constituição formal (aqui consideramos a abertura material consagrada no art. $5^{\circ}$, $\S 2^{\circ}$, da CF, que prevê o reconhecimento de direitos fundamentais implícitos, decorrentes do regime e dos princípios da Constituição, bem como direitos expressamente positivados em tratados internacionais).

6 Conforme Rawls (2000, p.90), a sociedade é interpretada como um empreendimento cooperativo para vantagem mútua. Dessa forma, a responsabilidade para se efetivar o direito à educação não é ação exclusiva do Estado, devendo a sociedade (setor privado, conselhos, ONGS, comunidades e família) agir em conjunto com os órgãos governamentais. 
Dessa forma, com vistas a definir diretrizes, metas e estratégias para assegurar a manutenção e desenvolvimento do ensino no Brasil, a Constituição Federal, em seu artigo 214 ${ }^{7}$, e a lei n.13.005/2014 ${ }^{8}$ estabeleceram a necessidade de publicação de um plano nacional de educação de duração decenal.

Conforme Libâneo (2012, p.181), entre as razões para a elaboração do PNE, figurava a premência de haver um plano de Estado, ou seja, um projeto de educação que tivesse duração independente dos governos no poder, garantindo a continuidade de políticas públicas para a educação.

Em atenção à obrigação constitucional do artigo 214 da Constituição Federal, após discussão da matéria no Congresso Nacional, foi promulgado o primeiro PNE pela lei n. 10.172/2001, com vigência de 2001-2010. Quanto ao primeiro PNE I, Martins e Souza (2014, p.173) expõem a seguinte crítica:

O PNE 2001-2010 continha 295 metas [...] de forma que por sua abrangência e sua dispersão, não dispunha de meios objetivos para um monitoramento e uma avaliação precisa de suas metas pela sociedade, o que contribuiu para que a maioria das metas não fosse alcançada. A ausência de planos de educação nas esferas estaduais e municipais, aliada à falta de indicadores confiáveis e a crise de credibilidade sofrida pelo PNE 2011-2010, resultante dos muitos vetos presidenciais que sofreu, pode explicar sua pouca efetividade.

No ano de 2009, com a iminência do término de vigência do PNE em 2010, surgiu a necessidade da elaboração de um novo planejamento para a próxima década da educação brasileira, buscando resultados mais efetivos do que aqueles apresentados no PNE 2001-2010.

Com isso, a discussão de um novo PNE começou em 2009, quando foram realizadas conferências municipais, estaduais e regionais prévias de educação, antecedendo à Conferência Nacional de Educação (CONAE) (LIBÂNEO, 2012, p.207).

A demora na tramitação do respectivo projeto de lei no Congresso Nacional levou à aprovação do PNE II apenas no ano de 2014, pela lei n. 13.005/2014, de modo que o atual PNE possui vigência para o decênio (2014-2024).

O Plano Nacional de Educação (2014-2024) é instituído, com a pretensão de ser um instrumento eficaz para a formulação e acompanhamento de políticas públicas educacionais aptas a mudar a realidade educacional do país.

No tocante à educação básica, o PNE foi estruturado em metas centrais aliadas a estratégias específicas que expressam diferentes objetivos e ações a serem desenvolvidas pelo Plano Nacional de Educação.

7 Art. 214. A lei estabelecerá o plano nacional de educação, de duração decenal, com o objetivo de articular o sistema nacional de educação em regime de colaboração e definir diretrizes, objetivos, metas e estratégias de implementação para assegurar a manutenção e desenvolvimento do ensino em seus diversos níveis, etapas e modalidades por meio de ações integradas dos poderes públicos das diferentes esferas federativas que conduzam a: [...] (BRASIL, 1988).

8 Art. $1^{\circ}$. É aprovado o Plano Nacional de Educação - PNE, com vigência por 10 (dez) anos, a contar da publicação desta Lei, na forma do Anexo, com vistas ao cumprimento do disposto no art. 214 da Constituição Federal. (BRASIL, 2014). 
Programa educação conectada: o uso de tecnologia para o cumprimento das metas de educação básica no plano nacional de educação

Tabela 1 - Metas PNE para Educação Básica (2014-2024)

\begin{tabular}{lll}
\hline Objetivo & Metas & Número de Ações Estratégicas \\
\hline Garantia do direito à educação básica com qualidade & Metas 1, 2, 3, 5, 6, 7, 9, 10 e 11. & 133 ações estratégicas \\
\hline Redução das desigualdades e valorização da diversidade & Metas 4 e 8. & 30 ações estratégicas \\
\hline Valorização dos profissionais da educação & Metas 15, 16, 17 e 18. & 31 ações estratégicas \\
\hline
\end{tabular}

Fonte: organizado pelos autores a partir de dados disponibilizados pelo Ministério da Educação-MEC ${ }^{9}$

Portanto, numa análise geral, as metas propostas pelo atual PNE (2014-2024) para a educação básica brasileira são extremamente ambiciosas, especialmente tendo em vista que o PNE anterior (2001-2010) não conseguiu atingir as metas a que se propôs ${ }^{10}$.

No entanto, em um país que ainda não possuiu um Sistema Nacional de Educação constituído" ${ }^{11}$, não há que se negar que a adoção de plano de educação decenal se trata de uma tentativa louvável para imprimir uma agenda institucional de ações na área educacional como política de Estado.

Dessa forma, como o Plano Nacional de Educação abrange todas as áreas da educação brasileira, é necessária uma interlocução maior entre os entes federativos aliados a uma participação crescente da sociedade ${ }^{12}$, especialmente para a formulação de planos de educação voltados às realidades regionais (planos de educação estaduais - PEEs) e locais (planos de educação municipais - PMEs).

O compromisso social pela melhoria da educação brasileira é um desafio complexo que deve ser enfrentado na busca por uma educação que reflita sobre as demandas impostas pela sociedade contemporânea, em especial para a qualificação para o trabalho, como preceitua o artigo 205 da Constituição Federal.

A educação básica brasileira deve desempenhar esse importante papel, para o desenvolvimento do país e formação de futuro capital humano condizente a um mercado de trabalho cada vez mais tecnológico, globalizado e com uma demanda maior por qualificação profissional.

Assim, é necessária a formulação de políticas públicas adequadas para o desenvolvimento do ensino básico, garantindo-se à ampliação do acesso e permanência ${ }^{13}$ e buscando meios eficazes para se cumprir os objetivos expostos nas metas para a educação básica no Plano Nacional de Educação.

9 Para conhecer melhor as metas do PNE para a educação básica. Ver. http://pne.mec.gov.br/images/pdf/pne_conhecendo_20_metas.pdf.

10 De acordo com Sudbrack et al. (2016, p.347), a checagem entre os dois PNEs permite afirmar que que não avançamos muito, embora tenhamos repetido as metas não alcançadas. As repetições de metas em planos diferentes, o não atingimento de resultados estimados resultam em planejamento de ações quase que parecidas, se não iguais em distintos períodos.

11 A lei que instituiu o PNE II (lei 13.005/2014) trouxe a seguinte disposição: Art. 13 - O poder público deverá instituir, em lei específica, contados 2 (dois) anos da publicação desta Lei, o Sistema Nacional de Educação, responsável pela articulação entre os sistemas de ensino, em regime de colaboração, para efetivação das diretrizes, metas e estratégias do Plano Nacional de Educação. No entanto, verifica-se que passados mais de 5 anos e o Sistema Nacional de Educação ainda não foi regulamentado (BRASIL, 2014).

12 Lei n. 13.005/2014. Art. $8^{\circ}, \S^{\circ}{ }^{\circ}$ - Os processos de elaboração e adequação dos planos de educação dos Estados, do Distrito Federal e dos Municípios, de que trata o caput deste artigo, serão realizados com ampla participação de representantes da comunidade educacional e da sociedade civil (BRASIL, 2014).

13 Art. 206. O ensino será ministrado com base nos seguintes princípios: I - igualdade de condições para o acesso e permanência na escola; (BRASIL, 1988). 


\section{POLÍTICAS PÚBLICAS PARA A EDUCAÇÃO BÁSICA}

Partindo da perspectiva do reconhecimento da educação como direito fundamental, a educação é classificada como direito fundamental de natureza social ${ }^{14}$, ou seja, é um direito que demanda uma ação prestacional por parte do Estado. Alexy (2013, p. 433-499), quanto à natureza prestacional de um direito fundamental, tece o seguinte entendimento:

são os direitos a uma ação positiva do Estado [...] Direito a prestação em sentido estrito são direitos do individuo, em face do Estado, a algo que o indivíduo se dispusesse de meios financeiros suficientes e se houvesse uma oferta suficiente no mercado, poderia também obter de particulares. Quando se fala em direitos fundamentais sociais, como por exemplo, direitos à assistência a saúde, ao trabalho, à moradia e à educação, quer-se primeiramente fazer menção a direitos a prestação em sentido estrito.

Diante isso, a educação é um direito que demanda mais que somente a sua positivação ${ }^{15}$ no texto constitucional, de modo que é necessário que o Estado, representado pelos poderes da República ${ }^{16}$, e a sociedade ${ }^{17}$ busquem meios para assegurar efetividade a esse direito por meio de programas capazes de garantir a promoção de justiça social ${ }^{18}$.

No tocante ao ensino básico, as políticas públicas de acesso, desenvolvimento e êxito escolar desempenham importante papel como programas governamentais destinados a garantir a universalização do direito à educação de maneira progressiva. Logo, a caracterização e conceituação de política pública não é uniforme, em vista de sua multidisciplinaridade de suas ações.

Segundo Bucci (2002, p. 241-243), políticas públicas "são programas de ação governamental [...] voltados ao atendimento das necessidades socialmente relevantes e politicamente determinadas".

Para Arzabe (2006, p. 63), políticas públicas compreendem “um conjunto de programas de ação governamental [...] dirigidos à realização de direitos e de objetivo social que buscam concretizar oportunidades para cada pessoa viver com dignidade e exercer seus direitos".

Por sua vez, Souza (2007, p. 69) leciona que "a formulação de políticas públicas constitui-se no estágio que governos democráticos traduzem seus propósitos [..] em programas e ações que produzirão resultados ou mudanças no mundo real".

14 Para da Silva (2014, p. 288), os direitos sociais, como dimensão dos direitos fundamentais do homem, são prestações positivas, proporcionadas pelo Estado, direta ou indiretamente, enunciadas em normas constitucionais, que possibilitam melhores condições de vida aos mais fracos, direitos que tendem a realizar a igualização de situações sociais desiguais.

15 De acordo com Bobbio (2004, p. 17), o problema grave de nosso tempo, com relação aos direitos do homem, não se trata de saber quais e quantos são esses direitos, qual é a sua natureza e seu fundamento, se são direitos absolutos ou relativos, mas sim qual é o modo mais seguro para garanti-los e para impedir que, apesar das solenes declarações, eles sejam continuamente violados.

16 Nesse aspecto, cabe destacar a proposição da PEC 26/2017, que acrescenta o artigo 75-A à Constituição. Art. 75-A. Os Poderes Executivo, Legislativo e Judiciário manterão, de forma integrada, sistema de avaliação de políticas públicas, com o objetivo de promover o aperfeiçoamento da gestão pública, na forma da lei. Disponível em: https://legis.senado.leg.br/ sdleg-getter/documento?dm=5377314\&ts=1562280109363\&disposition=inline

17 A Lei Complementar 131/2009 (Lei da Transparência), por meio do artigo 48, paragrafo único, inciso I e III, assegura a participação popular na gestão fiscal de elaboração e discussão dos planos, lei de diretrizes orçamentárias e orçamentos; assim como assegura a liberação ao pleno conhecimento e acompanhamento da sociedade, em tempo real, de informações pormenorizadas sobre a execução orçamentária e financeira, em meios eletrônicos de acesso publico. Disponível em http://www. planalto.gov.br/CCIVIL_03/leis/LCP/Lcp131.htm

18 Para Silva e Masson (2015, p.372), uma das peças-chave para a realização da justiça social é a universalização do ensino de qualidade, capaz de elevar a autoconsciência, a cidadania e a dignidade das pessoas, a fim de que se tornem sujeitos ativos aptos ao diálogo em sociedade. 
Programa educação conectada: o uso de tecnologia para o cumprimento das metas de educação básica no plano nacional de educação

Com a compreensão de um significado para as políticas públicas, é possível se observar o caráter intervencionista do Estado, o qual procura agir não mais de forma pontual, mas sim de maneira organizada e planejada para assegurar a implementação de direitos ${ }^{19}$, expostos de forma abstrata na Constituição.

No âmbito da educação básica brasileira, no período do Plano Nacional de Educação (2014-2024), uma série de políticas públicas de incentivo ao ensino básico está sendo desenvolvida pelo governo federal por intermédio do Ministério da Educação (MEC).

Tabela 2 - Políticas de Incentivo a Educação Básica no Brasil

\begin{tabular}{|c|c|c|}
\hline Programa & Regulamentação & Objetivo \\
\hline $\begin{array}{l}\text { Programa Novo Mais Educação } \\
\text { (PNME) }\end{array}$ & $\begin{array}{l}\text { Portaria } n^{\circ} 1.144 \text {, de } 10 \text { de outubro de } \\
2016 \text {, do Ministério da Educação (MEC) }\end{array}$ & $\begin{array}{l}\text { Melhorar a aprendizagem em língua portuguesa } \\
\text { e matemática no ensino fundamental, por meio } \\
\text { da ampliação da jornada escolar de crianças } \\
\text { e adolescentes, mediante a complementação } \\
\text { da carga horária de cinco ou quinze horas } \\
\text { semanais no turno e contraturno escolar }\end{array}$ \\
\hline $\begin{array}{l}\text { Programa de Fomento à } \\
\text { Implementação de Escolas em } \\
\text { Tempo Integral (EMTI) }\end{array}$ & $\begin{array}{l}\text { Portaria } n^{\circ} 1.145 \text {, de } 10 \text { de outubro de } \\
2016 \text {, do Ministério da Educação (MEC) }\end{array}$ & $\begin{array}{l}\text { Apoiar a ampliação da oferta de educação em } \\
\text { tempo integral no Ensino Médio nos estados } \\
\text { e Distrito Federal, de acordo com os critérios } \\
\text { estabelecidos nesta Portaria, por meio da } \\
\text { transferência de recursos para as Secretarias } \\
\text { Estaduais de Educação - SEE que participarem } \\
\text { do Programa. }\end{array}$ \\
\hline $\begin{array}{l}\text { Programa de Apoio ao Novo } \\
\text { Ensino Médio (NEM) }\end{array}$ & $\begin{array}{l}\text { Portaria } n^{\circ} 649 \text {, de } 10 \text { de julho de 2018, } \\
\text { do Ministério da Educação (MEC) }\end{array}$ & $\begin{array}{l}\text { Apoiar as secretarias de educação estaduais e } \\
\text { do Distrito Federal na elaboração e na execução } \\
\text { do Plano de Implementação de novo currículo } \\
\text { que contemple a Base Nacional Comum } \\
\text { Curricular - BNCC, os diferentes itinerários } \\
\text { formativos e a ampliação de carga horária para } \\
\text { mil horas anuais. }\end{array}$ \\
\hline
\end{tabular}

Fonte: organizado pelos autores a partir de dados disponibilizados pelo Ministério da Educação ${ }^{20}$

Assim, ao analisar o Plano Nacional de Educação (2014-2024), podemos encontrar esses programas governamentais como estratégias a serem desenvolvidas para cumprimento das Metas do $\mathrm{PNE}^{21}$ referentes à educação básica: Programa Novo Mais Educação (PNME) (Meta 6, estratégias 6.1,6.5 e 6.6), Programa de Fomento à Implementação de Escolas em Tempo Integral (EMTI) (Meta 6, estratégia 6.1), Programa de Apoio ao Novo Ensino Médio (NEM) (Meta 15, estratégia 15.6).

\section{PROGRAMA EDUCAÇÃO CONECTADA: IMPLEMETAÇAO DE TECNOLOGIA NA EDUCAÇÃO BÁSICA PARA CUMPRIMENTO DAS METAS NO PLANO NACIONAL DE EDUCAÇÃO}

$\mathrm{Na}$ era contemporânea, a humanidade vai se constituindo na chamada "sociedade do conhecimento", de modo que é imprescindível o acesso à educação, e mais do que isso, o acesso à tecnologia e demais conhecimentos disponíveis.

19 Grau (2001, p. 191) destaca que o direito - a norma jurídica - passa a ser dinamizada como instrumento do governo e deixa de ser única e exclusivamente a de ordenação. Enquanto instrumento de governo, então, o direito passa a ser atuado, tendo em vista a implementação de políticas públicas, políticas referidas a fins múltiplos e específicos.

20 Para um entendimento melhor sobre o desenvolvimento de políticas públicas para a educação básica. Ver: http://portal.mec. gov.br/index.php?option=com_content\&view=article\&id=12492\&ltemid=811.

21 Para conhecer as Metas e estratégias do PNE, ver: http://pne.mec.gov.br/18-planos-subnacionais-de-educacao/543-plano-nacional-de-educacao-lei-n-13-005-2014. 
Segundo Coutinho (2011, p. 08), na sociedade do conhecimento, o acesso à informação transcende as fronteiras do status ou classe social, permitindo a todas iguais oportunidades de acesso a informações.

A escola, como espaço que promove a educação, não pode ficar alheia aos recursos digitais que interferem em nosso modo de ser e conviver (WUNSCH, 2018, p. 58).

A utilização de novas tecnologias de informação e comunicação na educação transformam-se em importantes instrumentos para a democratização do ensino básico. Desse modo, para o cumprimento desse objetivo, várias iniciativas ${ }^{22}{ }^{23}$ estão sendo desenvolvidas pelo Ministério da Educação.

Além dessas iniciativas, pelo Decreto n. 9.204, de 23 de novembro de 2017, e pela Portaria $\mathrm{n}$. 1.602, de 28 de dezembro de 2017, do Ministério da Educação, em novembro de 2017 é implementado o Programa Educação Conectada, como uma política para o desenvolvimento da educação básica pela universalização do acesso à internet de alta velocidade e fomento ao uso pedagógico de tecnologias digitais na Educação Básica. Quanto a essa iniciativa, assim pontua da Silva (2010, p.109):

as discussões e as experiências de produção eletrônica de conhecimento propiciadas pela Internet têm muitas implicações para o conhecimento que ensinamos nas escolas. A Internet apresenta novas possibilidades para o currículo, colocando em questão fronteiras de disciplinas e hierarquias entre conhecimentos e entre experts e iniciantes.

Esse entendimento expressa uma nova perspectiva educacional, a qual Filho (2001) corrobora com a seguinte reflexão:

para cumprir seu papel humanista, a escola precisa mostrar aos alunos que existem outras culturas além da sua, outras perspectivas de vida, outras ideias. A escola deve possibilitar a seus alunos o contato com alunos de outras escolas, possibilitar viagens, encontros e toda sorte de projetos, próprios de cada escola, que a constituam num organismo vivo e atuante no seio da própria sociedade.

De fato, a tecnologia possibilita essa conexão e esse compartilhamento de ideias e experiências escolares. 0 primeiro passo é universalizar o acesso à internet nas escolas, possibilitando a inclusão digital no ambiente escolar.

Para isso, o programa Educação Conectada foi elaborado em quatro dimensões: 1) visão, 2) formação, 3) recursos educacionais digitais e 4) infraestrutura que se complementa e deve estar em equilíbrio, para que o uso de tecnologias digitais tenha efeito positivo na educação e possibilite a redução das desigualdades sociais.

22 Segundo Cordiolli (2011, p. 263), no que tange a programas com a iniciativa de integrar tecnologia na educação pública, destaca-se o programa Nacional de Tecnologia Educacional (Prolnfo), o qual foi instituído com o objetivo de disponibilizar o acesso a novas tecnologias de informação e comunicação às redes estatais de escolas de educação básica. Através desse programa, são disponibilizados nas escolas públicas equipamentos de informática com recursos digitais e conteúdos educacionais, na plataforma do sistema operacional Linux, além de diversas ferramentas educacionais baseadas em softwares livres.

23 Outro projeto que merece destaque é promovido pelo Centro Nacional de Mídias da Educação (CNME), pautado pelos princípios da igualdade de acesso, permanência na escola, liberdade de aprender, pluralismo de ideias e autonomia do professor. 0 projeto prevê a expansão de aulas presenciais com a participação de um segundo professor em estúdio, ou seja, os alunos das escolas participantes assistem aulas simultaneamente a partir de um estúdio, com a presença de educadores tanto no espaço de transmissão quanto em sala de aula (MEC, 2018). 
Programa educação conectada: o uso de tecnologia para o cumprimento das metas de educação básica no plano nacional de educação

Tabela 3 - Dimensões de desenvolvimento do Programa Educação Conectada

\begin{tabular}{ll}
\hline Dimensões & Ações a serem desenvolvidas \\
\hline Visão & $\begin{array}{l}\text { Estímulo ao planejamento por estados e municípios da inovação e tecnologia } \\
\text { como elementos transformadores da educação, promovendo valores como: } \\
\text { qualidade, contemporaneidade, melhoria de gestão e equidade; }\end{array}$ \\
\hline Formação & $\begin{array}{l}\text { Disponibilização de materiais e oferta de formação continuada a professores, } \\
\text { gestores e articuladores locais, e articulação com instituições de ensino } \\
\text { superior para incluir o componente tecnológico na formação inicial; }\end{array}$ \\
\hline Recursos Educacionais Digitais & $\begin{array}{l}\text { Acesso a recursos educacionais digitais e incentivo à aquisição e } \\
\text { socialização de recursos entre as redes de educação básica; }\end{array}$ \\
\hline Infraestrutura & $\begin{array}{l}\text { Apoio à aquisição e contratação dos serviços e equipamentos necessários } \\
\text { ao uso da tecnologia nas escolas públicas, inclusive serviços de conexão à } \\
\text { internet de alta velocidade. }\end{array}$ \\
\hline
\end{tabular}

Fonte: organizado pelos autores a partir de dados disponibilizados pela Portaria n. 1.602, de 28 de dezembro de 2017, do MEC.

Portanto, o Programa Educação Conectada visa fomentar ações para preparar o ambiente escolar para receber o acesso de conexão de internet de alta velocidade, destinando aos professores a possibilidade de conhecerem novos conteúdos educacionais ${ }^{24}$ e proporcionando aos alunos o contato com as novas tecnologias educacionais ${ }^{25}$. Nesse sentido, Netto $(2015$, p. 133$)$ destaca que

o mundo está passando por uma grande transformação. Encontram-se desafios em todas as áreas e formulam-se novas diretrizes para a educação. 0 cidadão deste novo tempo precisa ser criativo, participativo, atuante e preparado para enfrentar as mudanças que ocorrem na sociedade, os professores estão diante de novas exigências para ajudar os alunos a cumprir tais objetivos.

Dessa forma, em vista desses objetivos, a implementação do programa Educação Conectada será feita por fases ${ }^{26}$, compreendidas no período de 2017 a 2024, constituindo-se como um esforço conjunto $^{27}$ entre órgãos e entidades da União, dos Estados, do Distrito Federal, dos Municípios, escolas, setor empresarial e sociedade civil.

24 Dentro dessa perspectiva, Netto (2015, p.125) pontua que a formação dos educadores deve favorecer uma reflexão sobre teoria e prática, propiciando a experimentação de novas técnicas pedagógicas. Desse modo, o uso dos recursos de informática e das tecnologias de comunicação deve provocar reflexões sobre como, quando e por que utilizá-los, já que a meta da formação é o professor crítico e criativo.

25 Para Netto (2015, p.127), o desenvolvimento de novas tecnologias educacionais permite que a aprendizagem ocorra em diferentes lugares e por diferentes meios, ou seja, oferece-se alternativas de educação a distancia, o que possibilita a formação continua, com trabalhos cooperativos e interativos com a socialização de experiências e aprendizagem permanente.

26 Artigo 2², da portaria n. 1602/2017. O Programa de Inovação Educação Conectada será desenvolvido em fases, compreendidas no período de 2017 a 2024, a serem detalhadas em documento orientador publicado pelo Ministério da Educação - MEC (BRASIL, 2017).

27 Artigo $2^{\circ}$, do Decreto n. 9.204/2017. O Programa de Inovação Educação Conectada visa a conjugar esforços entre órgãos e entidades da União, dos Estados, do Distrito Federal, dos Municípios, escolas, setor empresarial e sociedade civil para assegurar as condições necessárias para a inserção da tecnologia como ferramenta pedagógica de uso cotidiano nas escolas públicas de educação básica (BRASIL, 2017). 
Tabela 4 - Implementação do Programa Educação Conectada

\begin{tabular}{lll}
\hline Fases & Período & Objetivos \\
\hline Indução & 2017 a 2018 & $\begin{array}{l}\text { Construção e implantação do Programa com metas } \\
\text { estabelecidas para alcançar o atendimento de 44,6\% dos } \\
\text { alunos da educação básica. }\end{array}$ \\
\hline Expansão & 2019 a 2021 & $\begin{array}{l}\text { Ampliação da meta para 85\% dos alunos da educação básica } \\
\text { e início da avaliação dos resultados. }\end{array}$ \\
\hline Sustentabilidade & 2022 a 2024 & $\begin{array}{l}\text { Alcance de 100\% dos alunos da educação básica, } \\
\text { transformando o Programa em Política Pública de Inovação e } \\
\text { Educação Conectada. }\end{array}$ \\
\hline
\end{tabular}

Fonte: organizado pelos autores a partir de dados disponibilizados pelo Ministério da Educação ${ }^{28}$

Logo, observa-se que o programa Educação Conectada se encontra articulado com a meta 7 do PNE, estratégia $7.15^{29}$, como um programa governamental para a educação básica, que integra suas ações no ensino fundamental para o cumprimento da Meta 5, pelas estratégias 5.3 e $5.4^{30}$, e no ensino médio, pelo cumprimento da Meta $3^{31}$.

Em 2019, transcorridos 2 anos após o lançamento do programa, é possível se observar os primeiros resultados, com a adesão de 5.179 municípios e com mais de 15 mil escolas beneficiárias de recursos do programa governamental (MEC, 2019).

No entanto, esse aspecto não encerra a questão sobre a importância desse programa governamental. 0 objetivo agora é a busca por formas ou meios de consolidá-lo, expandindo suas ações e conferindo mais eficácia e eficiência a sua atuação.

Quanto a essa preocupação, já se observa projetos de lei ${ }^{32}$ que visam tornar o programa Educação Conectada como política de Estado ${ }^{33}$, conferindo a ele status de diploma legal superior (de decreto para lei), visando evitar sua descontinuidade ou mesmo a diminuição de suas ações por decisão política do Poder Executivo.

28 Disponível em: http://educacaoconectada.mec.gov.br/o-programa/sobre.

29 Meta 7 do Plano Nacional de Educação. Fomentar a qualidade da educação básica em todas as etapas e modalidades, com melhoria do fluxo escolar e da aprendizagem de modo a atingir as seguintes médias nacionais para o Ideb. Estratégia 7.15) Universalizar, até o quinto ano de vigência deste PNE, o acesso à rede mundial de computadores em banda larga de alta velocidade e triplicar, até o final da década, a relação computador/aluno (a) nas escolas da rede pública de educação básica, promovendo a utilização pedagógica das tecnologias da informação e da comunicação (BRASIL, 2014).

30 Meta 5 do Plano Nacional de Educação. Alfabetizar todas as crianças, no máximo, até o final do 3o (terceiro) ano do ensino fundamental. Estratégias: 5.3) Selecionar, certificar e divulgar tecnologias educacionais para alfabetização de crianças, assegurada a diversidade de métodos e propostas pedagógicas, bem como o acompanhamento dos resultados nos sistemas de ensino em que forem aplicadas, devendo ser disponibilizadas, preferencialmente, como recursos educacionais abertos; 5.4) Fomentar o desenvolvimento de tecnologias educacionais e de práticas pedagógicas inovadoras que assegurem a alfabetização e favoreçam a melhoria do fluxo escolar e a aprendizagem dos (as) alunos (as), consideradas as diversas abordagens metodológicas e sua efetividade. (BRASIL, 2014).

31 Meta 3 do Plano Nacional de Educação. Universalizar, até 2016, o atendimento escolar para toda a população de 15 (quinze) a 17 (dezessete) anos e elevar, até o final do período de vigência deste PNE, a taxa líquida de matrículas no ensino médio para 85\% (oitenta e cinco por cento). (BRASIL, 2014).

32 O PL 9165/2017 aprovado pela Câmara dos Deputados transforma o Programa Educação Conectada em Política de Inovação Educação Conectada. Atualmente, a matéria encontra-se em tramitação no Senado Federal aquardando apreciação (PLC 142/2018). Disponível em: https://www.camara.leg.br/proposicoesWeb/fichadetramitacao?idProposicao=2163244 e https:// www25.senado.leg.br/web/atividade/materias/-/materia/134967.

33 Lima e Magalhães (2012, p. 12) ressaltam que se sublima, por exemplo, uma diferença nas políticas públicas entre aquelas denominadas Política de Estado e Política de Governo. As primeiras possuem um horizonte temporal maior, geralmente são políticas constitucionalizadas e envolvem a burocracia de mais de uma agência do Estado, já as segundas se realizam como parte de um programa maior, de duração mais curta e simples composição [...] ficando geralmente na competência dos próprios ministérios setoriais. 
Programa educação conectada: o uso de tecnologia para o cumprimento das metas de educação básica no plano nacional de educação

As exigências da sociedade do conhecimento impõem novos desafios ao modelo tradicional de escola. O programa Educação Conectada propõe uma transformação necessária, em que a tecnologia educacional desempenha papel central na inovação do sistema de ensino básico. Esse é apenas o início de um projeto que trará muitos benefícios tanto para educandos quanto para educadores.

\section{CONSIDERAÇÕES FINAIS}

Diante dos desafios da contemporaneidade, a escola, como ambiente que promove a educação, não deve ficar alheia à tecnologia e aos recursos digitais que interferem em nosso modo de ser e conviver. Logo, o debate sobre o uso de novas tecnologias na educação é de suma importância para a busca da universalização do ensino básico no Brasil.

Possibilitar uma reflexão sobre o emprego de tecnologia pelo programa Educação Conectada como estratégia para o cumprimento das metas para educação básica constantes no Plano Nacional de Educação foi o objetivo do presente artigo.

A partir dos estudos e considerações antecedentes sobre o Plano Nacional de Educação e sobre políticas públicas para educação básica, buscou-se delinear um contexto para o qual o emprego de tecnologia, pelo Programa Educação Conectada, perfaz um importante mecanismo para a realização das diretrizes para educação básica constantes nas metas do PNE.

Para isso, demonstrou-se que a expansão do acesso à internet aliada à utilização de recursos digitais modifica o processo de ensino-aprendizagem, abrindo novas perspectivas educacionais como o ensino a distância e permanente.

Desse modo, o Programa Educação Conectada é estruturado como uma estratégia no Plano Nacional de Educação (estratégia 7.15) que alia o uso de tecnologia para a educação básica, de modo que a articulação de suas ações otimiza o uso de tecnologia educacional para alfabetização no ensino fundamental e universalização do atendimento escolar no ensino médio.

Os primeiros resultados da interconexão desse programa governamental com as metas do PNE para a educação básica são evidentes, com o grande número de escolas e munícipios beneficiados. Assim, sua transformação em política de Estado pelos projetos em andamento no Congresso Nacional revela o papel de destaque da tecnologia educacional para a inovação e desenvolvimento da educação básica no Brasil.

\section{REFERÊNCIAS}

ALEXY, Robert. Teoria dos direitos fundamentais. 4. ed. São Paulo: Malheiros, 2013.

ARZABE, Patrícia Helena Massa. In: Bucci, Maria Paula Dallari (org). Políticas Públicas: reflexões sobre o conceito jurídico. São Paulo: Saraiva, 2006.

BOBBIO, Norberto. A Era dos direitos. 7. ed. Rio de Janeiro: Elsevier, 2004.

BRASIL. Constituição da República Federativa do Brasil de 1988. Disponível em: http://www.planalto. gov.br/ccivil_03/constituicao/constituicao compilado.ht 1988. Acesso em: 10 abr. 2020. 
BRASIL. Decreto n. 9.204 de 23 de novembro de 2017. Institui o Programa de Inovação Educação Conectada e dá outras providências. Disponível em: http://www.planalto.gov.br/ccivil_03/_Ato20152018/2017/Decreto/D9204.htm. Acesso em: 10 abr. 2020.

BRASIL. Lei Complementar 131 de 27 de maio de 2009. Acrescenta dispositivos à Lei Complementar no 101 , de 4 de maio de 2000, que estabelece normas de finanças públicas voltadas para a responsabilidade na gestão fiscal e dá outras providências, a fim de determinar a disponibilização, em tempo real, de informações pormenorizadas sobre a execução orçamentária e financeira da União, dos Estados, do Distrito Federal e dos Municípios. Disponível em: Disponível em http://www.planalto.gov.br/CCIVIL_03/ leis/LCP/Lcp131.htm_.Acesso em: 10 abr. 2020.

BRASIL. Lei n. 13.005 de 25 de junho de 2014.Aprova o Plano Nacional de Educação -PNE e dá outras providências. Disponível em: http://www.planalto.gov.br/ccivil_03/_Ato2011-2014/2014/Lei/L13005. htm. Acesso em: 10 abr. 2020.

BRASIL. Projeto de Lei n.9.165/2017. Institui a Política de Inovação Educação Conectada.. Disponível em: https://www.camara.leg.br/proposicoesWeb/fichadetramitacao?idProposicao=2163244Acesso em: 10 abr. 2020.

BRASIL. Proposta de Emenda a Constituição 26/2017. Disponível em: https://legis.senado.leg.br/ sdleggetter/documento?dm=5377314\&ts=1562280109363\&disposition=inline. Acesso em: 10 abr. 2020 .

BRASIL. Ministério da Educação. Centro Nacional de Mídias da Educação (CNME). Disponível em: http:// cnme.mec.gov.br/. Acesso em: 10 abr. 2020.

BRASIL. Ministério da Educação. Planejando a próxima década: conhecendo as $\mathbf{2 0}$ metas do Plano Nacional de Educação. Disponível em: http://pne.mec.gov.br/images/pdf/pne_conhecendo_20_metas. pdf. Acesso em: 10 abr. 2020.

BRASIL. Ministério da Educação. Plano Nacional de Educação - Lei n. 13.005/2014. . Disponível em: http://pne.mec.gov.br/18-planos-subnacionais-de-educacao/543-plano-nacional-de-educacaolei-n-13-005-2014. Acesso em: 10 abr. 2020.

BRASIL. Ministério da Educação. Portaria n.1.602 de 28 de dezembro de 2007. Dispõe sobre a implementação, junto às redes de educação básica municipais, estaduais e do Distrito Federal, das ações do Programa de Inovação Educação Conectada, instituído pelo Decreto no 9.204, de 23 de novembro de 2017. Disponível em: http://educacaoconectada.mec.gov.br/images/pdf/portaria_1602_28122017. pdf. Acesso em: 10 abr. 2020.

BRASIL. Ministério da Educação. Programas e Ações para a Educação básica. Disponível em: http:// portal.mec.gov.br/index. php?option=com_content\&view=article\&id=12492\&ltemid=811. Acesso em: 10 abr. 2020.

BRASIL. Ministério da Educação. Programa Educação Conectada. Disponível em: http://educacaoconectada. mec.gov.br/o-programa/sobre. Acesso em: 10 abr. 2020.

BUCCI, Maria Paula Dallari. Direito administrativo e políticas públicas. São Paulo: Saraiva, 2002.

CORDIOLLI, Marcos Antonio. Sistemas de ensino e políticas educacionais no Brasil. Curitiba: Ibpex, 2011. 
Programa educação conectada: o uso de tecnologia para o cumprimento das metas de educação básica no plano nacional de educação

COUTINHO, Carla. LISBÔA, Eliana. Sociedade da Informação, do conhecimento e da aprendizagem: Desafios para educação no século XXI. Revista de Educação, Vol. XVIII, 2011.

DA SILVA, Luiz Henron. A Escola no contexto da globalização. 15. ed. Rio de Janeiro: Editora Vozes, 2010.

FILHO, Geraldo Francisco. A educação brasileira no contexto histórico. São Paulo: Editora Alínea, 2001.

GRAU, Eros Roberto. A Ordem econômica na constituição de 1988. 6 ed. São Paulo: Malheiros, 2001.

LIBÂNEO, José Carlos. Educação escolar. políticas, estrutura e organização. 10. ed. São Paulo: Cortez,2012.

LIMA, Eric Santos; MAGALHÃES, Juliana Neuenschwander. Direitos Humanos e Políticas Públicas: As Duas Faces de Janus. XXI Encontro Nacional do Conpendi. MG: Uberlândia, 2012.

MARTINS, Angela Maria; SOUZA, Donaldo Bello de. Planos de Educação no Brasil: planejamento, políticas, práticas. 1. ed. São Paulo: Edições Loyola, 2014.

MASSON, Daiane Garcia; SILVA, Rogério Luiz Nery da. 0 direito fundamental social à educação como manifestação da igualdade e da liberdade, no contexto da política pública plano de desenvolvimento da educação (PDE). Disponível em: http://revista.unicuritiba.edu.br/index.php/RevJur/article/view/1465. Acesso em: 10 abr. 2020.

NAÇÕES UNIDAS. Declaração Universal dos Direitos Humanos. Disponível em: https://nacoesunidas. org/wp-content/uploads/2018/10/DUDH.pdf. Acesso em: 10 abr. 2020.

NETTO, Alvim Antônio de Oliveira. Novas tecnologias e universidade. 15. ed.. Rio de Janeiro: Editora Vozes, 2015.

RAWLS, John. Uma teoria de justiça. São Paulo: Martins Fontes, 2000.

SARLET, Ingo Wolfgang. Os direitos fundamentais na constituição de 1988. Revista Diálogo Jurídico. Bahia: Salvador, v. 1, n.1, 2001. Disponível em: https://www.passeidireto.com/arquivo/24084444/2-osdireitos-fundamentais-sociais-na-cf88-ingo-sarlet. Acesso em: 10 abr. 2020.

SILVA, José Afonso da. Curso de direito constitucional positivo. 37. ed. São Paulo: Malheiros, 2014.

SOUZA, Celina. Estado da Arte da Pesquisa em Políticas Públicas. In: HOCHMAN, Gilberto. Políticas Públicas no Brasil. Rio de Janeiro: Fio Cruz, 2007.

SUDBRACK, Edite Maria; JUNG, Hildegard Susana; CAUDURO, Tharles Gabriele. A educação superior para o empoderamento da classe trabalhadora: possibilidades e limites do PNE como instrumento de democratização da universidade. In: ALMEIDA, Maria de Lourdes Pinto de et al (orgs.). Estado, políticas públicas e educação. Campinas, SP. Mercado das Letras, 2016.

WUNSCH, Luana Priscila. Tecnologias na educação: conceito e práticas. Curitiba: Intersaberes. 2018. 